\title{
Effect of exercise training at different intensities on fat metabolism of obese men
}

Citation for published version (APA):

van Leijssen - Aggel, D. P. C., Saris, W. H. M., Wagenmakers, A. J. M., Senden, J. M. G., \& van Baak, M. A. (2002). Effect of exercise training at different intensities on fat metabolism of obese men. Journal of Applied Physiology, 92(3), 1300-1309. https://doi.org/10.1152/japplphysiol.00030.2001

Document status and date:

Published: 01/01/2002

DOI:

10.1152/japplphysiol.00030.2001

Document Version:

Publisher's PDF, also known as Version of record

\section{Please check the document version of this publication:}

- A submitted manuscript is the version of the article upon submission and before peer-review. There can be important differences between the submitted version and the official published version of record.

People interested in the research are advised to contact the author for the final version of the publication, or visit the DOI to the publisher's website.

- The final author version and the galley proof are versions of the publication after peer review.

- The final published version features the final layout of the paper including the volume, issue and page numbers.

Link to publication

\footnotetext{
General rights Owners
rights.

- You may freely distribute the URL identifying the publication in the public portal. please follow below link for the End User Agreement:

www.umlib.nl/taverne-license

Take down policy

If you believe that this document breaches copyright please contact us at:

repository@maastrichtuniversity.nl

providing details and we will investigate your claim.
}

Copyright and moral rights for the publications made accessible in the public portal are retained by the authors and/or other copyright owners and it is a condition of accessing publications that users recognise and abide by the legal requirements associated with these

- Users may download and print one copy of any publication from the public portal for the purpose of private study or research.

- You may not further distribute the material or use it for any profit-making activity or commercial gain

If the publication is distributed under the terms of Article $25 \mathrm{fa}$ of the Dutch Copyright Act, indicated by the "Taverne" license above, 


\title{
Effect of exercise training at different intensities on fat metabolism of obese men
}

\author{
DORIEN P. C. VAN AGGEL-LEIJSSEN, WIM H. M. SARIS, ANTON J. M. WAGENMAKERS, \\ JOAN M. SENDEN, AND MARLEEN A. VAN BAAK \\ Department of Human Biology, Nutrition, Toxicology, and Environmental Research Institute, \\ Maastricht University, 6200 MD Maastricht, The Netherlands
}

Received 12 January 2001; accepted in final form 9 November 2001

\begin{abstract}
Van Aggel-Leijssen, Dorien P. C., Wim H. M. Saris, Anton J. M. Wagenmakers, Joan M. Senden, and Marleen A. Van Baak. Effect of exercise training at different intensities on fat metabolism of obese men. $J$ Appl Physiol 92: 1300-1309, 2002; 10.1152/japplphysiol.00030.2001.— The present study investigated the effect of exercise training at different intensities on fat oxidation in obese men. Twenty-four healthy male obese subjects were randomly divided in either a low- [40\% maximal oxygen consumption $\left(\dot{\mathrm{V}}_{2}\right.$ max $\left.)\right]$ or high-intensity exercise training program $\left(70 \% \dot{\mathrm{V}}_{2}\right.$ max $)$ for 12 wk, or a nonexercising control group. Before and after the intervention, measurements of fat metabolism at rest and during exercise were performed by using indirect calorimetry, $\left[\mathrm{U}-{ }^{13} \mathrm{C}\right]$ palmitate, and $\left[1,2-{ }^{13} \mathrm{C}\right]$ acetate. Furthermore, body composition and maximal aerobic capacity were measured. Total fat oxidation did not change at rest in any group. During exercise, after low-intensity exercise training, fat oxidation was increased by $40 \%(P<0.05)$ because of an increased non-plasma fatty acid oxidation $(P<0.05)$. Highintensity exercise training did not affect total fat oxidation during exercise. Changes in fat oxidation were not significantly different among groups. It was concluded that lowintensity exercise training in obese subjects seemed to increase fat oxidation during exercise but not at rest. No effect of high-intensity exercise training on fat oxidation could be shown.
\end{abstract}

low intensity; stable isotopes; acetate correction factor; $\left[{ }^{13} \mathrm{C}\right]$ palmitate

OBESITY IS ASSOCIATED with an impaired ability to use fat as a fuel. This may contribute to the development and maintenance of large fat stores. Upper body obesity is associated with an impaired postabsorptive free fatty acid (FFA) utilization in skeletal muscle in women (6). Isoprenaline-induced fat oxidation and skeletal muscle FFA uptake are impaired in obese men, and no improvement was found after weight loss (1-3). Lean, formerly obese women have lower fasting fat oxidation rates compared with lean, never-obese women (32). Moreover, in Pima Indians, a population with a high prevalence of obesity, weight gain is association with a low 24-h fat-to-carbohydrate oxidation ratio (49). Several explanations have been proposed for this reduced

Address for reprint requests and other correspondence: D. P. C. van Aggel-Leijssen, Maastricht Univ., Dept. of Human Biology, P.O. Box 616, 6200 MD Maastricht, The Netherlands. fat utilization in obesity, such as a low activity of enzymes of $\beta$-oxidation (50), low skeletal muscle lipoprotein lipase activity (7), and impaired mobilization of fat stores (1). Interventions that will increase the capacity of the skeletal muscle to utilize fat may, therefore, make an important contribution to weight management in obese individuals and individuals at risk for obesity.

Endurance exercise training is known to increase fat oxidation during submaximal exercise at a fixed workload in lean subjects $(14,17,23,30,38)$. Cross-sectional studies also report higher fat oxidation during exercise after an overnight fast $(18,20,21,40,45)$ or with glucose $(19,47)$ in trained compared with sedentary men. Some studies also found an enhanced resting fat oxidation after endurance training $(5,31,34)$. Thus endurance exercise training appears to have the capacity to increase fat oxidation in lean subjects.

However, all studies reporting an effect of exercise training on fat metabolism involved moderate- to highintensity (HI) exercise training [60\% maximal oxygen consumption $\left(\dot{\mathrm{V}}_{2}\right.$ max $)$ ]. No studies with lower training intensities have been performed. In the obese population, low-intensity (LI) exercise training may be preferable to HI exercise training because of a lower risk of musculoskeletal injuries and better adherence. The impaired ability for fat mobilization and utilization in obese subjects might implicate that exercise training has a different effect on fat oxidation in obese compared with lean subjects. Because, during LI exercise, the proportion of lipids in the fuel mix oxidized is greater than during HI exercise (4), LI exercise training might improve the ability to oxidize fat more than HI exercise training. Therefore, the hypothesis of the present study is that fat metabolism of obese subjects can be improved by LI rather than HI exercise training. The present study compares the effects of LI ( $40 \%$ $\left.\dot{\mathrm{V}}_{\mathrm{O}_{2} \text { max }}\right)$ and $\mathrm{HI}\left(70 \% \dot{\mathrm{V}}_{2}\right.$ max $)$ endurance training on fat metabolism in obese men. The energy expenditure per training session was kept the same with LI and HI training, which meant that training sessions were twice as long in the LI program than in the HI pro-

The costs of publication of this article were defrayed in part by the payment of page charges. The article must therefore be hereby marked "advertisement" in accordance with 18 U.S.C. Section 1734 solely to indicate this fact. 
gram. Because fat oxidation (in $\mathrm{g} / \mathrm{min}$ ) is approximately the same during exercise at 40 and $70 \% \mathrm{Vo}_{2}$ max (16), total fat oxidation during the LI exercise sessions was twice that of the HI exercise sessions. The study was advertised as a training study, not as a weight-loss or weight-management study, in an attempt to prevent weight and body composition changes that might interfere with the effects of training on fat metabolism.

\section{METHODS}

\section{Subjects}

Twenty-four obese male subjects participated in this study. Physical characteristics are indicated in Table 1. All subjects were in good health, as assessed by medical history and physical examination. They did not take medication known to influence the variables measured and had a stable body weight $(<3 \mathrm{~kg}$ change) during 2 mo before selection. Subjects did not spend more than $2 \mathrm{~h} / \mathrm{wk}$ in sports activities and had no physically demanding jobs. Subjects were matched in groups of three for age, body mass index, fat percentage, and $\mathrm{VO}_{2}$ max per kilogram fat-free mass. Members of each group were subsequently randomly divided into three groups: the LI or HI exercise training group or the control (C) group. Subjects were requested to maintain their dietary habits during the study. The study protocol was approved by the Ethics Committee of Maastricht University. Written, informed consent was obtained from all subjects.

\section{Experimental Design}

Two of the three groups participated in an exercise-training intervention of $12 \mathrm{wk}$. The third group served as a nontraining C group. Measurements of body composition, $\dot{\mathrm{V}}_{2}$ max , and fat metabolism were made before the start of the exercise-training program and repeated within 2 wk after 12 wk of exercise training. The exercise training program was continued until all measurements were performed.

\section{Exercise Training}

The exercise training program consisted of cycling on an ergometer (Bodyguard Cardiocycle, Sandnes, Norway, or Excalibur, Lode, Groningen, The Netherlands) at either LI (40\% of predetermined $\mathrm{V}_{2}$ max $)$ or $\mathrm{HI}(70 \%$ of predetermined $\dot{\mathrm{V}}_{2}$ max). Eight subjects participated in the LI and eight subjects in the HI training program. Subjects trained during $12 \mathrm{wk}$, three times per week. Energy expenditure of each subject in each training session was $5 \mathrm{kcal} / \mathrm{kg}$ fat free mass $(\sim 350 \mathrm{kcal})$. Training duration for subjects in the LI and HI training program was $57.1 \pm 8.0$ and $32.8 \pm 2.5 \mathrm{~min}$, respectively. Heart rate was monitored continuously during the training sessions (Polar Electro, Oy, Finland). After 4 and 8 wk of exercise training, a $\mathrm{VO}_{2}$ max exercise test was performed, and the training workload and duration were adjusted if necessary. All training sessions took place at the laboratory under the supervision of a professional instructor.

\section{Measurements}

Body composition. Subjects were weighed on a digital balance accurate to $0.1 \mathrm{~kg}$ (Sauter D-7470, Ebingen, Germany). Height was measured to the nearest $0.1 \mathrm{~cm}$ by using a wall-mounted stadiometer (Seca, model 220, Hamburg, Germany). Body density was measured by hydrostatic weighing, with correction for residual lung volume measured by helium dilution with a spirometer (Volugraph 2000, Mijnhardt, The Netherlands) at the moment of underwater weighing. Body composition was calculated according to the formula of Siri (41).

$\dot{V}_{2} \max$. $\dot{\mathrm{V}}_{2}$ max for each subject was determined by an incremental exercise test on an electromagnetically braked cycle ergometer (Excalibur, Lode). After a warming-up period of $5 \mathrm{~min}$ at $100 \mathrm{~W}$, workload was increased every $4 \mathrm{~min}$ by 40 W until exhaustion. During the experiment, ventilatory and gas exchange responses were measured continuously by using indirect calorimetry (Oxycon $\beta$, Mijnhardt, The Netherlands). Heart rate was recorded continuously by an electrocardiogram. The highest oxygen uptake achieved over $30 \mathrm{~s}$ was taken as $\dot{\mathrm{V}}_{2}$ max.

Measurements of fat oxidation and rate of appearance of FFA during rest and exercise. Fat metabolism was studied by means of indirect calorimetry and stable isotope tracer methodology. To study fat metabolism, all subjects participated in two tracer tests before and after the training intervention, in which palmitate and acetate, respectively, were infused. The acetate-infusion test was performed to obtain a correction factor for the loss of ${ }^{13} \mathrm{C}$ label in the tricarboxylic acid cycle. Tracer tests were separated by a week to prevent carry over of the label. The sequence of the tracer tests was random. Subjects filled in a food and exercise questionnaire 3 days before the first tracer test. They were instructed to adjust to the same food and exercise habits 3 days before the second tracer test and the tracer tests after the training intervention to exclude bias by these factors.

Table 1. Subject characteristics before and after the intervention period in the LI and HI exercise, and C groups

\begin{tabular}{|c|c|c|c|c|c|c|}
\hline & \multicolumn{2}{|c|}{ LI } & \multicolumn{2}{|c|}{ HI } & \multicolumn{2}{|c|}{$\mathrm{C}$} \\
\hline Age, yr & $43.4 \pm 6.3$ & & $40.0 \pm 6.3$ & & $43.3 \pm 5.4$ & \\
\hline $\mathrm{BMI}, \mathrm{kg} / \mathrm{m}^{2}$ & $31.6 \pm 3.1$ & $31.7 \pm 3.1$ & $32.2 \pm 1.6$ & $32.1 \pm 1.3$ & $31.5 \pm 2.4$ & $31.4 \pm 2.5$ \\
\hline Body fat, $\%$ & $31.9 \pm 2.4$ & $31.5 \pm 2.2$ & $31.3 \pm 4.3$ & $31.8 \pm 4.4$ & $31.6 \pm 5.1$ & $31.7 \pm 5.0$ \\
\hline FFM, kg & $70.0 \pm 9.6$ & $70.7 \pm 8.7$ & $72.8 \pm 5.4$ & $71.8 \pm 6.7$ & $66.2 \pm 10.3$ & $65.7 \pm 9.5$ \\
\hline $\mathrm{V}_{2} \max , \mathrm{ml} / \mathrm{min}$ & $3191 \pm 532$ & $3556 \pm 542 *$ & $3312 \pm 448$ & $3820 \pm 453^{*} \dagger$ & $2944 \pm 443$ & $3019 \pm 557$ \\
\hline
\end{tabular}

Values are means $\pm \mathrm{SE}$ ( $n=8$ subjects). LI, low intensity; HI, high intensity; C, control; BMI, body mass index; FFM, free fatty mass; $\dot{\mathrm{V}}_{2}$ max , maximal oxygen consumption. *Significantly different from before intervention $(P<0.05)$. $†$ Change significantly different from $\mathrm{C}$ $(P<0.05)$. 


\section{$\left[U_{-}{ }^{13} \mathrm{C}\right]$ palmitate Infusion}

This experiment was performed at least $36 \mathrm{~h}$ after the last exercise bout. Subjects were asked to refrain from consuming naturally ${ }^{13} \mathrm{C}$-enriched food products for $1 \mathrm{wk}$ before the experiment. After an overnight fast, subjects came to the laboratory by car or bus. Subjects remained in semi-supine position throughout the first $2.5 \mathrm{~h}$ of the experiment. Catheters were inserted in an arm vein for infusion of the palmitate tracer and retrogradely into a contralateral dorsal hand vein for blood sampling. The cannulated hand was placed in a hot box, in which warm air of $60^{\circ} \mathrm{C}$ circulated, to obtain arterialized venous blood. A baseline arterialized blood sample was taken after $30 \mathrm{~min}$. Baseline expired breath was sampled in a 15-ml vacutainer tube (Becton Dickinson, Meyland Cedex, France) to determine background enrichment.

Immediately after baseline samples were obtained, subjects were given an intravenous dose of $1.0 \mu \mathrm{mol} / \mathrm{kg}$ $\mathrm{NaH}^{13} \mathrm{CO}_{3}$ to prime the bicarbonate pool. A constant infusion $0.0053 \mu \mathrm{mol} \cdot \mathrm{kg}^{-1} \cdot \mathrm{min}^{-1}\left[\mathrm{U}^{13} \mathrm{C}\right]$ palmitate was then started [time $(t)=0$ ] by using IVAC pumps (IVAC Medical, Amersfoort, The Netherlands). These infusions were continued for $120 \mathrm{~min}$ with the subjects in a semi-supine position. Subsequently, subjects started to exercise in a sitting position for $1 \mathrm{~h}$ at $50 \%$ of pretraining $\dot{\mathrm{V}}_{2}$ max on a cycle ergometer (Excalibur, Lode). The infusion rate during exercise was doubled to minimize changes in isotopic enrichment.

Carbon dioxide consumption $\left(\dot{\mathrm{V}}_{\mathrm{CO}_{2}}\right)$ and oxygen consumption $\left(\dot{\mathrm{V}}_{2}\right)$ were measured by using an open-circuit ventilatedhood system (Oxycon $\beta$ ). At rest and during exercise, $\dot{\mathrm{V}}_{2}$ and $\dot{\mathrm{V}}_{2}$ were measured during $5 \mathrm{~min}$ immediately before taking a breath sample for measurement of ${ }^{13} \mathrm{CO}_{2}$ enrichment. The accuracy of the ventilated-hood system for measuring $\dot{\mathrm{V}}_{\mathrm{CO}_{2}}$ and $\dot{\mathrm{V}}_{2}$ was tested regularly to be within $5 \%$. Breath samples were taken at $t=100,110$, and $120 \mathrm{~min}$ at rest and at $t=40,50$, and 60 min during exercise.

The exact infusion rate of $\left[\mathrm{U}_{-}{ }^{13} \mathrm{C}\right]$ palmitate was determined for each experiment by measuring the concentrations of the infusates (see Sample Analyses). Blood samples were taken at $t=90,100,110$, and $120 \mathrm{~min}$ of rest and at $t=30$, 40,50 , and 60 min during exercise. Blood samples were put into an EDTA or heparin and $300-\mu l$ glutathione $(45 \mu \mathrm{g} / 1$ saline) containing chilled $10-\mathrm{ml}$ tube and immediately centrifuged at for $10 \mathrm{~min}$ at $800 \mathrm{~g}$ at $4^{\circ} \mathrm{C}$. Plasma was stored at $-80^{\circ} \mathrm{C}$ until analyses. EDTA containing blood was used for analyses of glucose, FFA, insulin, triglyceride (TG), and palmitate concentrations as well as the plasma enrichment of palmitate. Heparin and glutathione containing blood was used for analysis of catecholamines. During rest $(t=0,90$, and $120 \mathrm{~min}$ ) and exercise $(t=30$ and $60 \mathrm{~min})$, blood was sampled for the measurement of oxygen saturation (hemoxymeter OSM2, Copenhagen, Denmark) to check that the arterialization was at least $90 \%$. Before infusion, the palmitate tracer $\left(60 \mathrm{mg}\right.$ of potassium salt of $\left[\mathrm{U}-{ }^{13} \mathrm{C}\right]$ palmitate, enrichment $=98.9 \%$, Cambridge Isotope Laboratories, Andover, MA) was bound to albumin by dissolving it in heated $\left(60^{\circ} \mathrm{C}\right)$ sterile water and passing it through a $0.2-\mu \mathrm{m}$ filter into a $5 \%$ warm $\left(60^{\circ} \mathrm{C}\right)$ human serum albumin solution to make a $0.670 \mathrm{mM}$ solution.

\section{$\left[1,2-{ }^{13} \mathrm{C}\right]$ acetate Infusion}

Palmitate oxidation rates were corrected for loss of tracer in products of the tricarboxylic acid cycle by using the acetate correction factor previously described by Sidossis et al. (39) and Schrauwen et al. (36). The protocol for the acetateinfusion experiment was the same as for the palmitateinfusion experiment, except that no blood was sampled. The acetate tracer (sodium salt of $\left[1,2-{ }^{13} \mathrm{C}\right]$ acetate, enrichment $=$ $99 \%$, Cambridge Isotope) was dissolved in $0.9 \%$ saline. The acetate infusion rate was $0.0496 \mu \mathrm{mol} \cdot \mathrm{kg}^{-1} \cdot \mathrm{min}^{-1}$ at rest and was doubled during exercise. Before the acetate infusion was started, an intravenous dose of $1.0 \mu \mathrm{mol} / \mathrm{kg} \mathrm{NaH}{ }^{13} \mathrm{CO}_{3}$ was given to prime the bicarbonate pool.

\section{Sample Analysis}

Plasma total FFA, glycerol, and TG concentrations were measured on a COBAS FARA centrifugal spectrophotometer. For analysis of plasma total FFA concentrations, a nonesterified fatty acids (FA) C kit (Wako Chemicals, Neuss, Germany) was used. Plasma glycerol and TG concentrations were analyzed by using a glycerol kit (Boehringer, Mannheim, Germany). Plasma insulin concentrations were measured with a double-antibody radioimmunoassay (insulin RIA 100, Pharmacia, Uppsala, Sweden). Plasma catecholamine concentrations were analyzed by HPLC with electrochemical detection (42).

Chemical and isotopic purities $(99 \%)$ of the palmitate and acetate tracers were checked by ${ }^{1} \mathrm{H}$ - and ${ }^{13} \mathrm{C}-\mathrm{NMR}$ and gas chromatography (GC)/mass spectrometry (MS). Breath samples were analyzed for ${ }^{13} \mathrm{C} /{ }^{12} \mathrm{C}$ ratio by using a $\mathrm{GC}$-isotope ratio mass spectrometer (GC-IRMS, Finnigan MAT 252, Bremen, Germany). For determination of the plasma palmitate concentration, FFA were extracted from plasma, isolated by thin-layer chromatography, and derived to methyl esters. Palmitate concentration was determined on an analytical GC with flame ionization detection, which used heptadecanoic acid as an internal standard. The isotope tracer-to-tracee ratio (TTR) of palmitate was determined by using GC combustion isotope ratio MS, with correction for the extra methyl group in the derivative.

The concentration of the acetate infusate was determined on a COBAS FARA with an enzymatic method kit 148261 (Boehringer). The concentration of the palmitate infusate was determined as described above for plasma samples.

\section{Calculations}

Total fat oxidation was calculated by the following equation (8)

$$
\text { Total fat oxidation }=1.67 \times \dot{\mathrm{V}}_{2}-1.67 \times \dot{\mathrm{V}}_{\mathrm{CO}_{2}}
$$

with $\dot{\mathrm{V}}_{\mathrm{CO}_{2}}$ and $\dot{\mathrm{V}}_{2}$ in liters per minute. The value 1.67 is derived from the volumes of oxygen consumed and carbon dioxide produced in oxidation of $1 \mathrm{~g}$ of fat.

Because no estimation of protein oxidation is included in this calculation of fat oxidation, fat oxidation will be overestimated. However, because fat oxidation is compared before and after exercise training, this overestimation will not influence the outcome.

Total FA oxidation was determined by converting the rate of total fat oxidation to its molar equivalent, with the assumption that the average molecular weight of TG is 860 $\mathrm{g} / \mathrm{mol}$ and multiplying the molar rate of TG oxidation by three because each molecule contains $3 \mathrm{~mol}$ of FA.

${ }^{13} \mathrm{C}$ enrichment of breath carbon dioxide and plasma palmitate is expressed as a TTR. TTR was defined as ${ }^{13} \mathrm{C} /$ $\left.{ }^{12} \mathrm{C}\right)_{\mathrm{sa}}-\left({ }^{13} \mathrm{C} /{ }^{12} \mathrm{C}\right)_{\mathrm{bk}}$ in which sa is sample and bk is background.

Fractional recovery of infused acetate ${ }^{13} \mathrm{C}$ label in breath carbon dioxide (AR) was calculated as

$$
\mathrm{AR}=\left(\mathrm{TTR} \mathrm{CO}_{2} \times \dot{\mathrm{V}} \mathrm{CO}_{2}\right) / \mathrm{F}
$$

where $\mathrm{F}$ is the infusion rate of ${ }^{13} \mathrm{C}$ (in $\mathrm{mmol} / \mathrm{min}$ ). 
The rate of $\left[\mathrm{U}-{ }^{13} \mathrm{C}\right]$ palmitate oxidation was calculated as Plasma palmitate oxidation

$$
=\left(\mathrm{TTR} \mathrm{CO}_{2} \times \dot{\mathrm{V}}_{\mathrm{CO}_{2}}\right) /(\mathrm{TTR} \text { plasma } \times \mathrm{AR}) 1,000
$$

The average $\dot{\mathrm{V}}_{\mathrm{CO}_{2}}$ over the last three time points at rest and during exercise was used.

Total plasma FA oxidation was then calculated by dividing palmitate oxidation by the fractional contribution of palmitate to the total FFA concentration. The average fraction palmitate/FFA was used in this equation, and total plasma FA oxidation per time point was calculated during the rest and exercise period.

Non-plasma-derived FA oxidation ( $\mu \mathrm{mol} / \mathrm{min})$, which refers to intramuscular TGs and plasma triacylglycerol, was calculated at rest and during exercise as the average total FA oxidation minus the average plasma FFA oxidation.

Rate of appearance $\left(R_{a}\right)$ of palmitate in plasma, which under steady-state conditions is equal to the rate of disappearance minus tracer infusion rate, was calculated as

$$
\mathrm{R}_{\mathrm{a}}=[(\mathrm{TTR} \text { infusate/TTR plasma })-1] \mathrm{F}
$$

Percentage of plasma FFA cleared from the circulation that was oxidized was calculated as

$$
\% \mathrm{R}_{\mathrm{a}} \text { oxidized }=\text { plasma FFA oxidation } / \mathrm{R}_{\mathrm{a}} \mathrm{FFA}
$$

\section{Statistics}

Data are expressed as means \pm SE. Changes within groups were analyzed by using the Wilcoxon signed rank test. Differences in basal values and in changes among groups were tested by the Kruskal-Wallis test. Post hoc testing was done by the Mann-Whitney test. Where appropriate, $P$ values of the post hoc comparisons were corrected according to Bonferroni inequalities. Spearman correlation coefficients $(r)$ were calculated between the changes because of the intervention (LI or HI training or no training) in norepinephrine and epinephrine concentrations during exercise and between the changes in total fat oxidation, $\mathrm{R}_{\mathrm{a}} \mathrm{FFA}$ and plasma FFA, and glycerol concentrations during exercise. A $P$ value of $<0.05$ was regarded as statistically significant.

\section{RESULTS}

\section{Subject Characteristics}

The exercise training intervention did not lead to significant changes in body weight and body composi- tion (Table 1). Both LI and HI exercise training significantly increased $\dot{\mathrm{V}}_{2}$ max and $\dot{\mathrm{V}}_{2}$ max/free fatty mass (FFM; $P<0.05$ ), whereas the $\mathrm{C}$ group showed no change. Changes in $\dot{\mathrm{V}}_{2}$ max and $\dot{\mathrm{V}}_{2}$ max/FFM were significantly different between the $\mathrm{HI}$ and $\mathrm{C}$ groups $(P<0.05)$. The absolute workload during the exercise test (50\% of pretraining $\dot{\mathrm{V}}_{2}$ max $)$ in the LI, HI, and $\mathrm{C}$ groups was $102 \pm 33,104 \pm 23$, and $92 \pm 24 \mathrm{~W}$, respectively. Workloads were not significantly different among groups. Attendance at the exercise training sessions was $89.4 \pm 7.7 \%$ for the LI group and $92.6 \pm$ $5.5 \%$ for the HI group.

\section{Fat Oxidation at Rest}

Data from indirect calorimetry showed that relative fat oxidation during the last $20 \mathrm{~min}$ of the resting period, expressed as respiratory exchange ratio (RER), was not different after the intervention from before (Table 2). Total FA oxidation (Table 2) and percentage of fat oxidized of total energy expenditure (Fig. 1A) did not change in any of the groups because of the intervention either. Preintervention total and relative fat oxidation were not significantly different between groups. Energy expenditure at rest was slightly lower after the intervention in all groups but was only significantly lower in the HI group $(P<0.05)$.

Plasma palmitate enrichment was at plateau (change $=-2.5 \%$ ) during the last 20 min of the resting period. Therefore, tracer calculations of plasma palmitate oxidation were made with the use of the values of plasma palmitate enrichment measured over the 100to $120-$ min period. These tracer calculations were corrected by acetate recovery factors, which were measured and calculated over the same time points. The fractional recovery of acetate increased gradually at rest from $22.3 \pm 2.5 \%$ at $100 \mathrm{~min}$ to $25.4 \pm 2.9 \%$ at 120 min after the start of the tracer infusion. Exercise training did not influence the acetate recovery factor significantly.

Plasma FFA oxidation at rest was significantly decreased in the HI training group after training $(P<$ 0.05) (Fig. 1C), whereas in the LI and $\mathrm{C}$ groups there was no change. The change in the HI group was sig-

Table 2. Energy expenditure and substrate oxidation results from indirect calorimetry at rest and during exercise before and after the intervention period in the LI, HI and control (C) groups

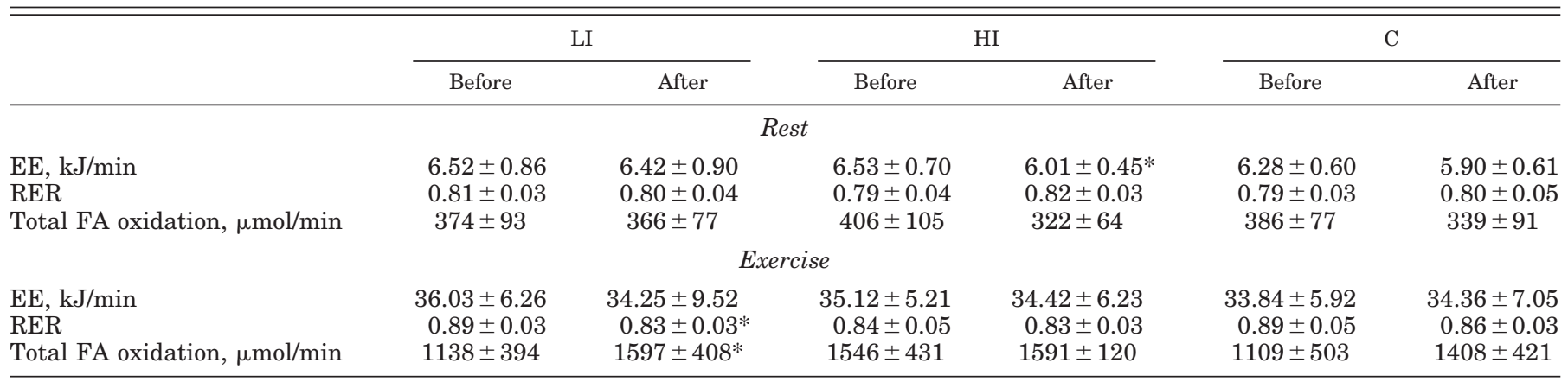

Values are means \pm SE. EE, energy expenditure; RER, respiratory exchange ratio; FA, fatty acid. * Significantly different from before intervention $(P<0.05)$. 

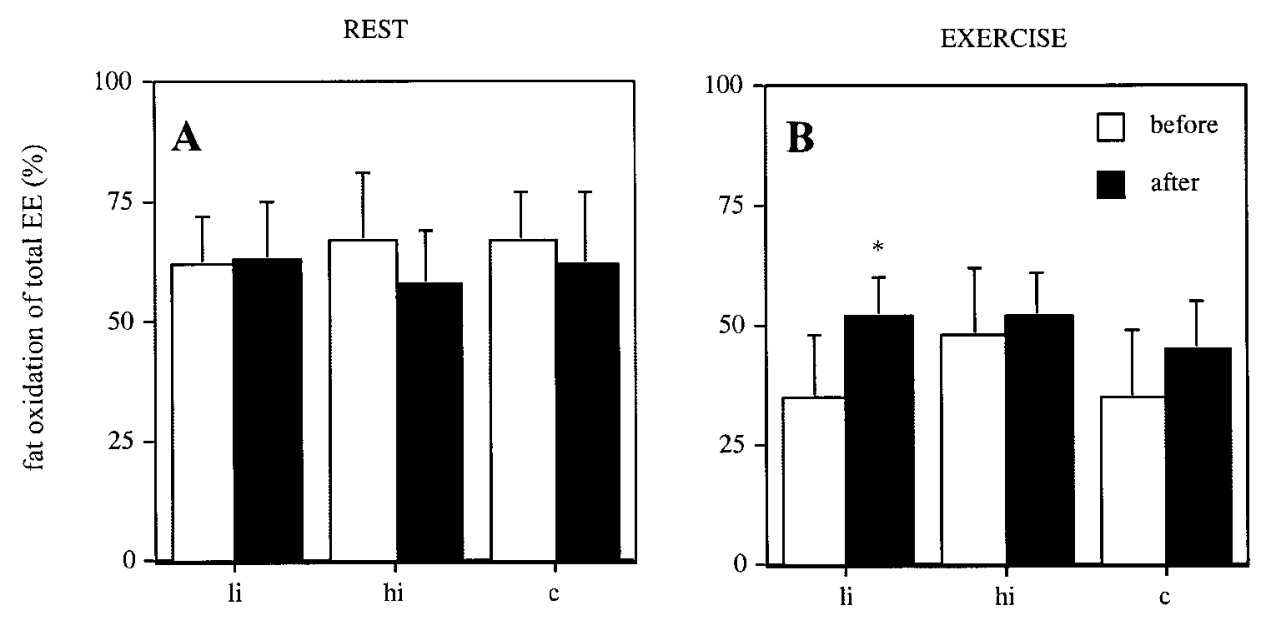

Fig. 1. Fat oxidation as a percentage of total energy expenditure (EE) $(A$ and $B$ ), plasma free fatty acid (FFA) oxidation $(C$ and $D)$, and non-plasma fatty acid (FA) oxidation [intramuscular and very low-density lipoprotein triglyceride (VLDL-TG); $E$ and $F$ ] over the last 20 min during rest and exercise in the low-intensity (LI) exercise, high-intensity (HI) exercise, and control (C) groups at rest $(A, C$ and $E)$ and during exercise $(B, D$ and $F)$ before and after the intervention. Values are means $\pm \mathrm{SE}$. *Significantly different from before intervention $(P<0.05)$.
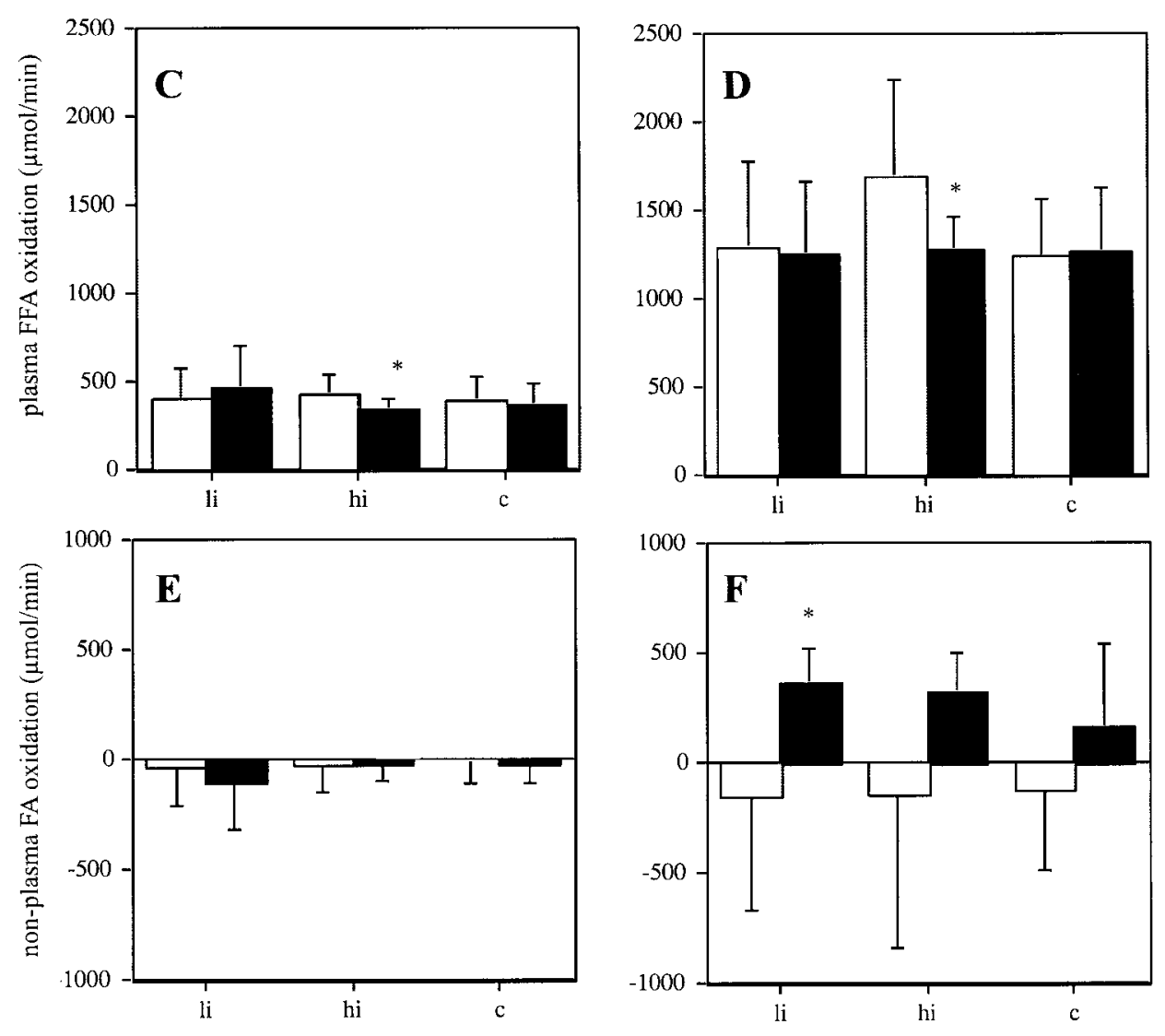

nificantly different from the $\mathrm{LI}$ and $\mathrm{C}$ groups $(P<$ $0.05)$. Non-plasma-derived FA oxidation (plasma triacylglycerol and intramuscular TGs; calculated as total FA oxidation - plasma FFA oxidation) at rest was not significantly different from zero before as well as after exercise training (Fig. $1 E$ ).

$R_{\mathrm{a}}$ of FFA at rest was significantly higher after training in the LI group $(P<0.05)$ (Fig. $2 A)$. The change was significantly different from the HI group $(P<0.05)$. FFA oxidation as a percentage of the $\mathrm{R}_{\mathrm{a}}$ of FFA did not change because of the intervention (Fig. $2 A$, numbers in parentheses). Plasma concentrations of FFA (Fig. 3A) and glycerol (Fig. $3 B$ ) were not significantly different after the intervention from before.
Plasma TG concentrations were significantly reduced in the HI group after the intervention $(P<0.05)$ (Fig. $3 C$ ). Average plasma FFA, glycerol, and TG concentrations, calculated over the last 20 min of rest and exercise, before the intervention were not significantly different between groups. Plasma insulin, epinephrine, and norepinephrine concentrations were not changed after the intervention (Table 3).

\section{Fat Oxidation During Exercise}

During the last 20 min of exercise, RER was significantly decreased in the LI group after exercise training, whereas, in the $\mathrm{HI}$ and $\mathrm{C}$ groups, RER did not 

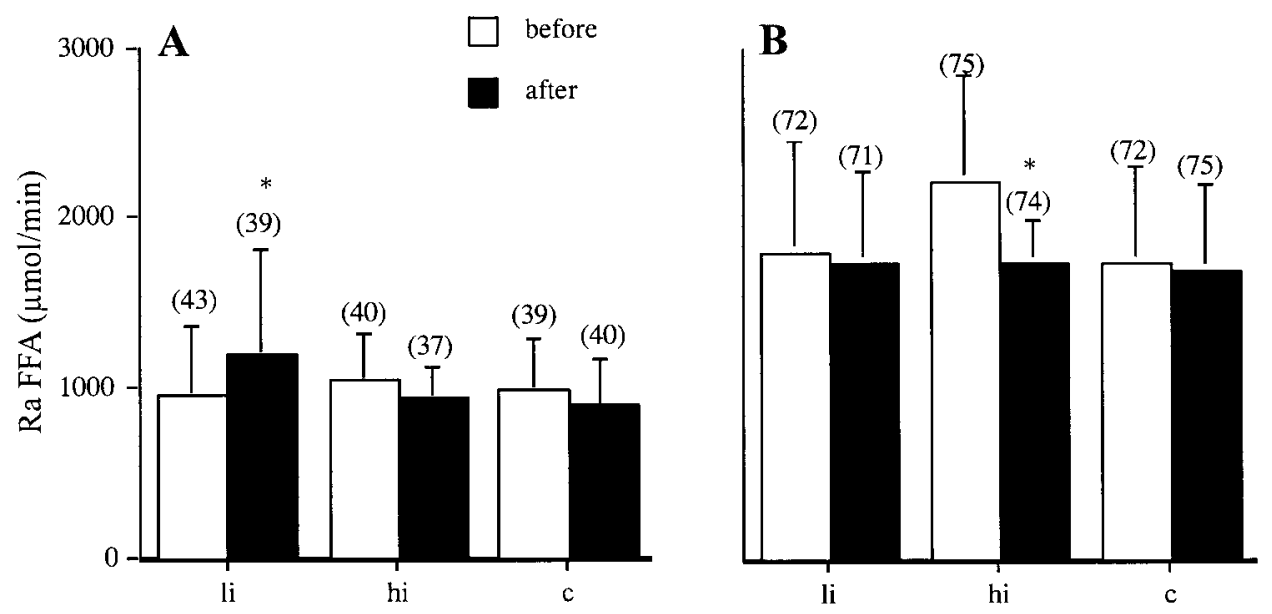

Fig. 2. Rate of appearance $\left(\mathrm{R}_{\mathrm{a}}\right)$ of FFA (in $\mu \mathrm{mol} / \mathrm{min}$ ) in the $\mathrm{LI}, \mathrm{HI}$, and $\mathrm{C}$ groups at rest $(A)$ and during exercise $(B)$ before and after the intervention. Values are means \pm SE. Numbers in parentheses are percentage of $R_{a}$ of FFA oxidized. *Significantly different from before intervention $(P<0.05)$.

change. In addition, total fat oxidation over the last 20 min was significantly increased in the LI group after training compared with before training $(P<0.05$; Table 2). Fat oxidation as percentage of total energy expenditure was also increased in the LI group after the exercise intervention (Fig. 1B). However, the change in fat oxidation due to the intervention (LI or HI exercise training or no training) was not significantly different among groups. Preintervention fat oxidation rates were not significantly different among the groups.

Plasma palmitate enrichment was at semi-plateau (change $=-3.6 \%$ ) during the last $20 \mathrm{~min}$ of the exercise period. The acetate correction factor increased gradually during exercise from $69.0 \pm 8.2 \%$ after 40 $\min$ to $72.2 \pm 8.3 \%$ after $60 \mathrm{~min}$ of exercise at $50 \%$ $\dot{\mathrm{V}}_{2}$ max before the intervention. The intervention did not change the acetate recovery factor. Plasma FFA oxidation during exercise was significantly decreased in the HI group $(P<0.05)$ after training whereas there were no changes in the LI and C groups (Fig. $1 D$ ). Plasma FFA oxidation before the intervention was not significantly different among the groups. Non-plasma FA oxidation was significantly increased in the LI group $(P<0.05)$ but not in the $\mathrm{HI}$ and $\mathrm{C}$ groups (Fig. $1 F)$. The changes were not significantly different among groups. Non-plasma FA oxidation before the intervention was not significantly different from zero.

$\mathrm{R}_{\mathrm{a}}$ of FFA was significantly decreased in the HI group after training $(P<0.05)$ but did not change in the LI and $\mathrm{C}$ groups, and changes were not significantly different among groups. The percentage of FFA oxidized from the $\mathrm{R}_{\mathrm{a}}$ of FFA was not changed after the intervention (Fig. 2B, numbers in parentheses). Plasma FFA, glycerol, and TG concentrations after exercise training were significantly reduced from before exercise in the HI group $(P<0.05$; Fig. 3$)$. However, concentrations before the intervention were not significantly different among the groups. Interindividual differences in TG concentrations were high in the LI group (Fig. 3C). However, excluding a subject with TG concentrations over $4,000 \mu \mathrm{mol} / \mathrm{l}$ did not change the statistical outcome. After exercise training, plasma epiniphrine concentrations were significantly decreased in all groups during exercise $(P<0.05$; Table 3). Plasma norepinephrine was significantly decreased during exercise in the HI and $\mathrm{C}$ groups $(P<$ 0.05; Table 3). The LI group showed a similar tendency. Changes in plasma norepinephrine concentrations during exercise did not significantly correlate with changes in total fat oxidation $(r=-0.33, P=0.12), \mathrm{R}_{\mathrm{a}}$ FFA $(r=0.31, P=0.14)$, plasma FFA $(r=0.12, P=$ $0.60)$, and glycerol concentrations $(r=0.30, P=0.16)$ during exercise. In addition, changes in plasma epinephrine concentrations during exercise did not significantly correlate with changes in total fat oxidation $(r=-0.22, P=0.30), \mathrm{R}_{\mathrm{a}} \mathrm{FFA}(r=-0.13, P=0.55)$, plasma FFA $(r=-0.20, P=0.93)$, and glycerol concentrations $(r=0.04, P=0.85)$ during exercise. Plasma insulin concentrations were not different after the intervention for all groups (Table 3).

\section{DISCUSSION}

Many studies have shown that moderate-intensity to $\mathrm{HI}$ exercise training $\left(>60 \% \dot{\mathrm{V}}_{2}\right.$ max $)$ increases total fat oxidation during exercise in lean subjects $(14,17,23$, $30,38)$. The results of the present study show that exercise training in obese men is effective in increasing total fat oxidation when exercise training is executed at LI $\left(40 \% \dot{\mathrm{V}}_{2}\right.$ max $)$. Exercise training at $\mathrm{HI}(70 \%$ $\dot{\mathrm{V}}_{\mathrm{O}_{2} \text { max }}$ ) does not significantly increase total fat oxidation during moderate-intensity exercise. In contrast to the findings during exercise, no changes in fat metabolism because of exercise training were found under resting conditions.

The increase in fat oxidation during moderate-intensity exercise in the LI training group is in agreement with a comparable study in upper-body obese women (46). In this study, relative fat oxidation increased significantly in upper body obese women after executing the same LI exercise training protocol as the upperbody obese men in the present study. The percentage of total energy expenditure coming from fat oxidation during exercise increased from 35 to $52 \%(P<0.05)$ in the LI training group. This is similar to data reported 

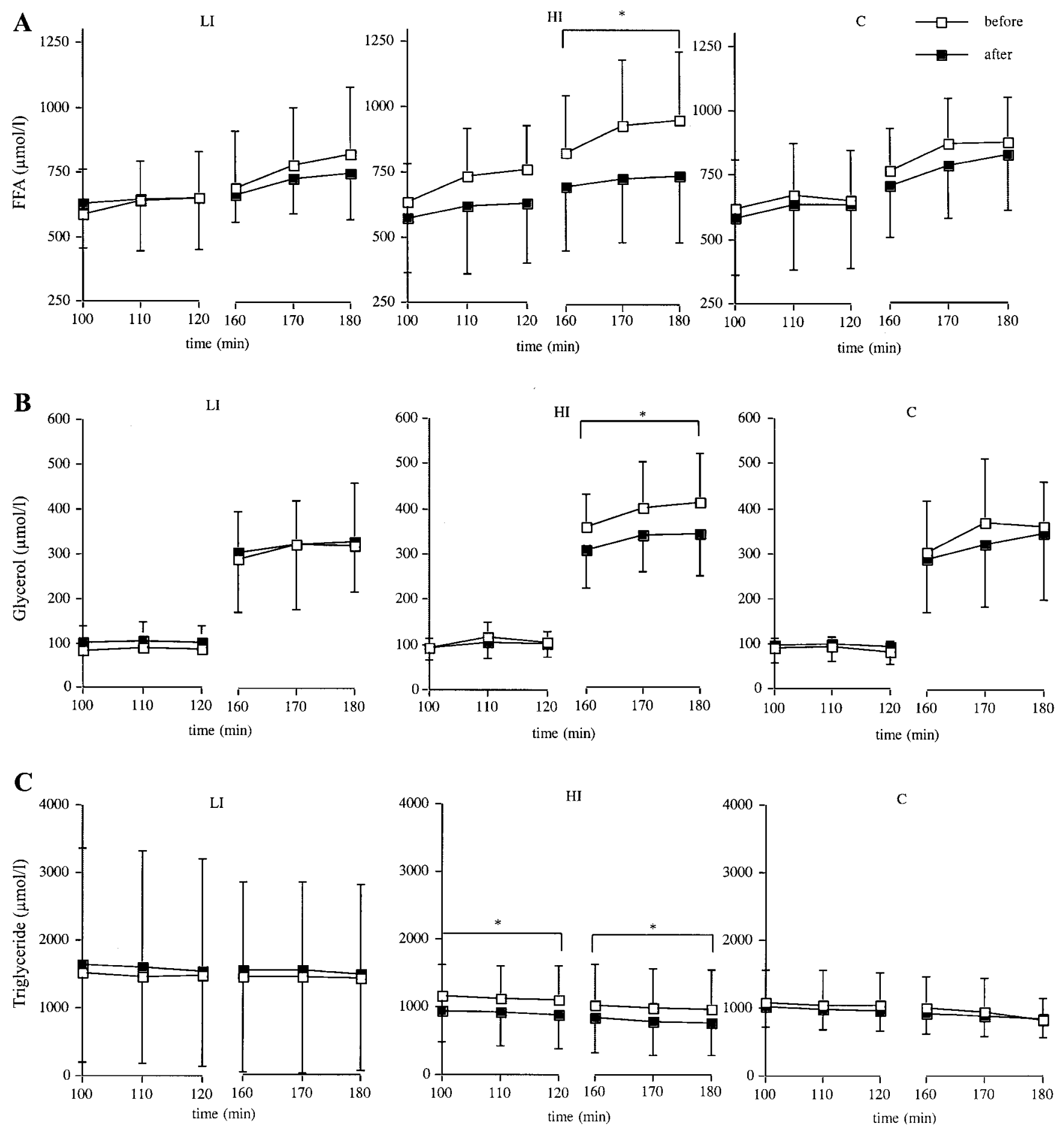

Fig. 3. Plasma FFA (A), glycerol (B), and triglyceride (TG; $C$ ) concentrations during rest (minutes 100 to 120 ) and exercise (minutes 160 to 180 ) before and after the intervention in the LI, HI, and C groups. Values are means \pm SE. *Significantly different from before intervention $(P<0.05)$

in upper-body obese women after LI exercise training (46) and lean men after HI exercise training (17).

The significant increase in total fat oxidation in the LI group during exercise $(P<0.05)$ is not explained by an increased plasma FFA oxidation but rather by an increase in non-plasma FA oxidation $(P<0.05)$. In the HI group, total fat oxidation during exercise failed to increase. Although, in this group, non-plasma FA oxidation increased slightly but not significantly, this was just enough to compensate for the significant decrease of the plasma FFA oxidation $(P<0.05)$. The decrease in plasma FFA oxidation in the HI group by exercise is paralleled by a significant decrease of the $R_{a}$ of FFA in plasma. Together with the decrease of plasma FFA and 
Table 3. Average plasma concentrations of epinephrine, norepinephrine, and insulin in the LI, HI, and C groups before and after the intervention

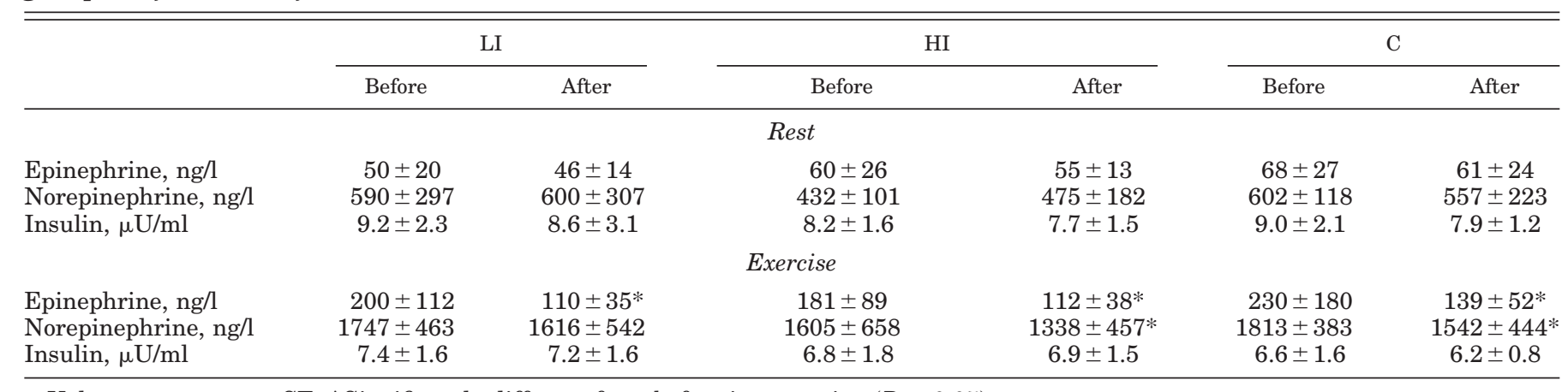

Values are means \pm SE. * Significantly different from before intervention $(P<0.05)$.

glycerol concentration seen after exercise training $(P<$ $0.05)$, this seems to point to a reduced rate of adipose tissue lipolysis in the HI group (15).

A reduction in plasma catecholamine concentrations during exercise has been found in all groups. This reduction can be explained by habituation to the exercise experiment because this effect has been found in the $\mathrm{C}$ as well as in the exercise-training groups. The changes in catecholamine concentrations during exercise after 12 wk show no correlation with changes in total fat oxidation, $\mathrm{R}_{\mathrm{a}}$ of FFA and plasma FFA, and glycerol concentrations. Therefore, the changes in catecholamine concentrations are not likely to affect the outcome of the present study with respect to substrate use.

The increase in non-plasma FA oxidation after exercise training can either implicate an increase in intramuscular triglycerides (IMTG) oxidation and/or an increase in very low-density lipoprotein (VLDL)-TG oxidation. However, the data in the present study are not able to distinguish between the two. No consistent data on training effects on VLDL-TG or IMTG oxidation are available in the literature. Some studies reported an increased IMTG oxidation by exercise training $(18,30)$, whereas another study showed no change (20). IMTG content does not appear to be correlated with obesity in humans $(11,29)$ but does correlate with obesity in rats (43). IMTG content is increased in trained compared with untrained human muscle $(20$, 24). Data on the contribution of VLDL-TG to fat oxidation during exercise in the literature are not consistent $(13,20,26)$. An exercise-induced TG clearance from the circulation is suggested because lipoprotein lipase enzyme activity is increased in skeletal muscle by exercise $(28,37)$. This is in agreement with the decreased plasma TG concentrations after exercise training in the HI group, but this decrease is not seen in the LI group. The cleared plasma TG may be used as fuel in the muscle.

Despite significant changes in plasma FFA oxidation, the percentage of FFA oxidized from the FFA released in plasma did not change because of exercise training and was $\sim 40 \%$ at rest and $73 \%$ during exercise. This indicates that the $R_{a}$ of FFA is not rate limiting in plasma fat oxidation. In lean, untrained men, comparable data were reported at rest (30\%) and during exercise at $40 \% \quad \dot{V}_{\mathrm{O}_{2} \max }(75 \%)$ (48). At $60 \%$ maximum external power, the percentage of plasma FFA oxidation was found to be $76 \%$ (45), with no difference after exercise training. Friedlander et al. (9), however, showed a significantly increased percentage of FFA oxidized from FFA released in plasma after exercise training (from 51 to $61 \%$ at $65 \%$ pretraining $\dot{\mathrm{V}}_{\mathrm{O}_{2} \text { max }}$ ). In all of these studies, corrections were made for the loss of ${ }^{13} \mathrm{C}$ or ${ }^{14} \mathrm{C}$ label by using the bicarbonate correction factor rather than the acetate recovery factor, as in the present study.

Although considerable effects of exercise training on fat oxidation in obese subjects are found during exercise, at rest these effects are less obvious. Neither after LI nor after HI exercise training were effects found on fat oxidation. However, other parameters measured suggest that fat metabolism is more positively influenced by LI training (significantly increased $R_{a}$ of FFA) than by HI training (significantly decreased plasma FFA oxidation). In lean subjects, the effects of exercise training on fat metabolism at rest are not consistent. Some studies reported an increased fat oxidation at rest after exercise training $(5,30,31)$, whereas others found no change $(9,10,38)$. Cross-sectional studies comparing trained and untrained lean subjects at rest showed higher fat oxidation rates in trained compared with untrained subjects $(21,33,44)$. Obese subjects are known to have a diminished capacity to mobilize and oxidize FA during $\beta$-adrenergic stimulation (1) and have a reduced postabsorptive FFA utilization by the muscle (6). However, the present study showed that fat oxidation during exercise can be improved by exercise training. Because the extra FA oxidized in the trained state are mainly coming from non-plasma FA pools (IMTG and VLDL-TG) rather than from plasma FFA (lipolysis from adipose tissue), the question can be raised whether training will help to reduce adipose mass in obese subjects. However, the depleted nonplasma FA pools after exercise could be restored by FFA from adipose tissue, which could implicate the importance of trafficking of substrates between tissues. The IMTG pool is suggested to be restored by FFA from plasma TG or adipose tissue by activating muscle lipoprotein lipase after exercise and diminishing the 
lipoprotein lipase activity in adipose tissue $(22,25,27)$. A study in rats reported that plasma FFA is an important source for synthesis of IMTG (12). However, whether exercise training-induced changes in fat utilization during exercise contribute to the positive/favorable effects of exercise training on body mass in obese subjects remains to be studied.

\section{Methodological Considerations}

The test conditions in the present study did not allow the subjects to exercise $36 \mathrm{~h}$ before the test. This implicates that only the more permanent effects of exercise training on fat oxidation were measured and not the acute effects of an exercise bout.

Although the present study showed significant differences in FA oxidation and non-plasma FA oxidation, no difference was observed between the exercise groups and the $\mathrm{C}$ group. This might be explained by the limited number of subjects in all of the three groups. Furthermore, the slightly, but not significantly, lower RER before the intervention in the HI group, compared with the LI and C groups, might have influenced the outcome in the HI group. These factors should be taken into account in the interpretation of the effect of exercise training on fat oxidation.

In the present study, the acetate recovery factor was used to correct for label loss in the tricarboxylic acid cycle (39) during the palmitate-infusion test. The acetate recovery factor has a high intra-individual reproducibility but varies between subjects (36). The acetate recovery factor is correlated with basal metabolic rate, percentage of body fat, and RER (35). Therefore, measurements of acetate recovery were performed individually both before and after exercise training. At rest, the acetate recovery has a large impact on plasma FFA oxidation rates because only about $25 \%$ of ${ }^{13} \mathrm{C}$ label was recovered in expired breath. During exercise, label recovery was $\sim 72 \%$. When the acetate recovery factor was been ignored, plasma palmitate oxidation was underestimated by $\sim 75 \%$ at rest and $\sim 28 \%$ during exercise. During exercise before the intervention and at rest, calculated non-plasma FFA oxidation rates were not significantly different from zero, although, in some subjects, values were below zero. These negative values may indicate that values for plasma palmitate oxidation rates were over-corrected by using the acetate correction factor. This overcorrection may indicate that more $\left[{ }^{13} \mathrm{C}\right]$ acetate is trapped in the tricarboxylic acid cycle than $\left[{ }^{13} \mathrm{C}\right]$ palmitate. Training did not affect the acetate recovery factor. However, it is not known whether exercise training has a different effect on loss of label from acetate or palmitate.

In conclusion, LI exercise training is effective in increasing fat oxidation during exercise but not at rest. No effect of HI exercise training on total fat oxidation could be shown.

The authors thank Moniek Homan for supervision of the exercise training sessions, Jos Stegen for analytical assistance, and Judith Graat and Vanessa Blokdijk for assistance during the experiments. We also thank Lode BV for providing cycle ergometers.
This study was supported by Netherlands Heart Association Grant 95040.

\section{REFERENCES}

1. Blaak EE, Van Baak MA, Kemerink GJ, Pakbiers MT, Heidendal GA, and Saris WH. $\beta$-Adrenergic stimulation of energy expenditure and forearm skeletal muscle metabolism in lean and obese men. Am J Physiol Endocrinol Metab 267: E306E315, 1994.

2. Blaak EE, Van Baak MA, Kemerink GJ, Pakbiers MT, Heidendal GA, and Saris WH. $\beta$-Adrenergic stimulation of skeletal muscle metabolism in relation to weight reduction in obese men. Am J Physiol Endocrinol Metab 267: E316-E322, 1994.

3. Blaak EE, van Baak MA, Kester AD, and Saris WH. $\beta$-Adrenergically mediated thermogenic and heart rate responses: effect of obesity and weight loss. Metabolism 44: 520-524, 1995.

4. Bouchard C, Després JP, and Tremblay A. Exercise and obesity. Obes Res 1: 133-147, 1993.

5. Calles-Escandón J, Goran MI, O'Connell M, Nair KS, and Danforth E Jr. Exercise increases fat oxidation at rest unrelated to changes in energy balance or lipolysis. Am J Physiol Endocrinol Metab 270: E1009-E1014, 1996.

6. Colberg SR, Simoneau JA, Thaete FL, and Kelley DE. Skeletal muscle utilization of free fatty acids in women with visceral obesity. J Clin Invest 95: 1846-1853, 1995.

7. Ferraro RT, Eckel RH, Larson DE, Fontvieille AM, Rising R, Jensen DR, and Ravussin E. Relationship between skeletal muscle lipoprotein lipase activity and 24-hour macronutrient oxidation. J Clin Invest 92: 441-445, 1993.

8. Frayn KN. Calculation of substrate oxidation rates in vivo from gaseous exchange. J Appl Physiol 55: 628-634, 1983.

9. Friedlander AL, Casazza GA, Horning MA, Buddinger TF, and Brooks GA. Effects of exercise intensity and training on lipid metabolism in young women. Am J Physiol Endocrinol Metab 275: E853-E863, 1998.

10. Friedlander AL, Casazza GA, Horning MA, Usaj A, and Brooks GA. Endurance training increases fatty acid turnover, but not fat oxidation, in young men. J Appl Physiol 86: 20972105, 1999.

11. Goodpaster BH and Kelley DE. Role of muscle in triglyceride metabolism. Curr Opin Lipidol 9: 231-236, 1998.

12. Guo $\mathbf{Z}$ and Jensen MD. Intramuscular fatty acid metabolism evaluated with stable isotopic tracers. J Appl Physiol 84: 16741679, 1998.

13. Havel RJ, Pernow B, and Jones NL. Uptake and release of free fatty acids and other metabolites in the legs of exercising men. J Appl Physiol 23: 90-99, 1967.

14. Henriksson J. Training induced adaptation of skeletal muscle and metabolism during submaximal exercise. J Physiol (Lond) 270: 661-675, 1977.

15. Hetenyi G Jr, Perez G, and Vranic M. Turnover and precursor-product relationships of nonlipid metabolites. Physiol Rev 63: 606-667, 1983.

16. Howley ET, Duncan GE, and Del Corral P. Optimum intensity of exercise for fat oxidation (Abstract). Med Sci Sports Exerc 29: S199, 1997.

17. Hurley BF, Nemeth PM, Martin WHd Hagberg JM, Dalsky GP, and Holloszy JO. Muscle triglyceride utilization during exercise: effect of training. J Appl Physiol 60: 562-567, 1986.

18. Jansson E and Kaijser L. Substrate utilization and enzymes in skeletal muscle of extremely endurance-trained men. J Appl Physiol 62: 999-1005, 1987.

19. Jeukendrup AE, Mensink M, Saris WH, and Wagenmakers AJ. Exogenous glucose oxidation during exercise in endurancetrained and untrained subjects. J Appl Physiol 82: 835-840, 1997.

20. Kiens B, Essen Gustavsson B, Christensen NJ, and Saltin B. Skeletal muscle substrate utilization during submaximal exercise in man: effect of endurance training. J Physiol (Lond) 469: 459-478, 1993.

21. Klein S, Coyle EF, and Wolfe RR. Fat metabolism during low-intensity exercise in endurance-trained and untrained men. Am J Physiol Endocrinol Metab 267: E934-E940, 1994. 
22. Ladu MJ, Kapsas H, and Palmer WK. Regulation of lipoprotein lipase in muscle and adipose tissue during exercise. $J$ Appl Physiol 71: 404-409, 1991.

23. Martin WH 3rd, Dalsky GP, Hurley BF, Matthews DE, Bier DM, Hagberg JM, Rogers MA, King DS, and Holloszy JO. Effect of endurance training on plasma free fatty acid turnover and oxidation during exercise. Am J Physiol Endocrinol Metab 265: E708-E714, 1993.

24. Morgan TE, Short FA, and Cobb LA. Effect of long-term exercise on skeletal muscle lipid composition. Am J Physiol 216: 82-86, 1969.

25. Nikkilä EA. Lipoprotein Lipase. Chicago, IL: Evener, 1987, p. 187-199.

26. Nikkilä EA and Konttinen A. Effect of physical activity on postprandial levels of fats in serum. Lancet 1: 1151-1154, 1962.

27. Oscai LB, Essig DA, and Palmer WK. Lipase regulation of muscle triglyceride hydrolysis. J Appl Physiol 69: 1571-1577, 1990.

28. Oscai LB, Patterson JA, Bogard DL, Beck RJ, and Rothermel BL. Normalization of serum triglycerides and lipoprotein electrophoretic patterns by exercise. Am J Cardiol 30: 775-780, 1972.

29. Phillips DI, Caddy S, Ilic V, Fielding BA, Frayn KN, Borthwick AC, and Taylor R. Intramuscular triglyceride and muscle insulin sensitivity: evidence for a relationship in nondiabetic subjects. Metabolism 45: 947-950, 1996.

30. Phillips SM, Green HJ, Tarnopolsky MA, Heigenhauser GF, Hill RE, and Grant SM. Effects of training duration on substrate turnover and oxidation during exercise. J Appl Physiol 81: 2182-2191, 1996.

31. Poehlman ET, Gardner AW, Arciero PJ, Goran MI, and Calles Escandon J. Effects of endurance training on total fat oxidation in elderly persons. J Appl Physiol 76: 2281-2287, 1994.

32. Ranneries C, Bulow J, Buemann B, Christensen NJ, Madsen J, and Astrup A. Fat metabolism in formerly obese women. Am J Physiol Endocrinol Metab 274: E155-E161, 1998.

33. Romijn JA, Coyle EF, Sidossis LS, Gastaldelli A, Horowitz JF, Endert E, and Wolfe RR. Regulation of endogenous fat and carbohydrate metabolism in relation to exercise intensity and duration. Am J Physiol Endocrinol Metab 265: E380-E391, 1993.

34. Romijn JA, Klein S, Coyle EF, Sidossis LS, and Wolfe RR. Strenuous endurance training increases lipolysis and triglyceride-fatty acid cycling at rest. J Appl Physiol 75: 108-113, 1993.

35. Schrauwen P, Blaak EE, Van Aggel-Leijssen DPC, Borghouts LB, and Wagenmakers AJM. Determinants of the acetate recovery factor: implications for estimation of ${ }^{13} \mathrm{C}$ substrate oxidation. Clin Sci (Colch) 98: 587-592, 2000.

36. Schrauwen P, Van Aggel-Leijssen DP, Van Marken Lichtenbelt WD, Van Baak MA, Gijsen AP, and Wagenmakers AJ. Validation of the $\left[{ }^{1,2-13} \mathrm{C}\right]$ acetate recovery factor for correction of $\left[\mathrm{U}-{ }^{13} \mathrm{C}\right]$ palmitate oxidation rates in humans. $J$ Physiol (Lond) 513: 215-223, 1998.
37. Seip RL, Angelopoulos TJ, and Semenkovich CF. Exercise induces human lipoprotein lipase gene expression in skeletal muscle but not adipose tissue. Am J Physiol Endocrinol Metab 268: E229-E236, 1995.

38. Sial S, Coggan AR, Hickner RC, and Klein S. Traininginduced alterations in fat and carbohydrate metabolism during exercise in elderly subjects. Am J Physiol Endocrinol Metab 274: E785-E790, 1998.

39. Sidossis LS, Coggan AR, Gastaldelli A, and Wolfe RR. A new correction factor for use in tracer estimations of plasma fatty acid oxidation. Am J Physiol Endocrinol Metab 269: E649E656, 1995.

40. Sidossis LS, Wolfe RR, and Coggan AR. Regulation of fatty acid oxidation in untrained vs. trained men during exercise. Am J Physiol Endocrinol Metab 274: E510-E515, 1998.

41. Siri WE. The gross composition of the body. Adv Biol Med Physiol 4: 239-280, 1956.

42. Smedes F, Kraak JC, and Poppe H. Simple and fast solvent extraction system for selective and quantitative isolation of adrenaline, noradrenaline and dopamine from plasma and urine. $J$ Chromatogr A 231: 25-39, 1982.

43. Storlien LH, Jenkins AB, Chisholm DJ, Pascoe WS, Khouri S, and Kraegen EW. Influence of dietary fat composition on development of insulin resistance in rats. Relationship to muscle triglyceride and omega-3 fatty acids in muscle phospholipid. Diabetes 40: 280-289, 1991.

44. Tremblay A, Conveney S, Després JP, Nadeau A, and Prud'homme D. Increased resting metabolic rate and lipid oxidation in exercise-trained individuals: evidence for a role of $\beta$-adrenergic stimulation. Can J Physiol Pharmacol 70: 13421347, 1992.

45. Turcotte LP, Richter EA, and Kiens B. Increased plasma FFA uptake and oxidation during prolonged exercise in trained vs. untrained humans. Am J Physiol Endocrinol Metab 262: E791-E799, 1992.

46. Van Aggel-Leijssen DPC, Saris WHM, Wagenmakers AJ, Hul GB, and Van Baak MA. The effect of low intensity exercise training on fat oxidation of obese women. Obes Res 9: 86-96, 2001.

47. Van Loon LJC, Jeukendrup AE, Saris WHM, and Wagenmakers AJM. Effect of training status on fuel selection during submaximal exercise with glucose ingestion. J Appl Physiol 87: 1413-1418, 1999.

48. Wolfe RR, Klein S, Carraro F, and Weber JM. Role of triglyceride-fatty acid cycle in controlling fat metabolism in humans during and after exercise. Am J Physiol Endocrinol Metab 258: E382-E389, 1990.

49. Zurlo F, Lillioja S, Esposito Del Puente A, Nyomba BL, Raz I, Saad MF, Swinburn BA, Knowler WC, Bogardus C, and Ravussin E. Low ratio of fat to carbohydrate oxidation as predictor of weight gain: study of 24-h RQ. Am J Physiol Endocrinol Metab 259: E650-E657, 1990.

50. Zurlo F, Nemeth PM, Choksi RM, Sesodia S, and Ravussin E. Whole-body energy metabolism and skeletal muscle biochemical characteristics. Metabolism 43: 481-486, 1994. 